\title{
Indication of pre-surgical radiochemotherapy enhances psychosocial morbidity among patients with resectable locally advanced rectal cancer
}

\author{
V. BENCOVA*, I. KRAJCOVICOVA, J. SVEC* \\ 1st Department of Oncology, Faculty of Medicine, Comenius University, Bratislava, Slovakia \\ *Correspondence: jsvec@ousa.sk,viera.bencova@hafling.sk
}

Received December 6, 2015 / Accepted April 13, 2016

\begin{abstract}
Patients with cancer experience stress-determined psychosocial comorbidities and behavioural alterations. Patients expectation to be cured by the first line surgery and their emotional status can be negatively influenced by the decision to include neoadjuvant long-course radiotherapy prior to surgical intervention. From the patient's perspective such treatment algorithmindicates incurability of the disease. The aim of this study was to analyse the extent and dynamics of stress and related psychosocial disturbances among patients with resectable rectal cancer to whom the neoadjuvant radiochemotherapy before surgery has been indicated.Three standardised assessment tools evaluating psychosocial morbidity of rectal cancer patients have been implemented: The EORTC QLQ C30-3, the EORTC QLQ CR29 module and the HADS questionnaires previously tested for internal consistency were answered by patients before and after long-course radiotherapy and after surgery and the scores of clinical and psychosocial values were evaluated by means of the EORTC and HADS manuals.

The most profound psychosocial distress was experienced by patients after the decision to apply neoadjuvant radiotherapy and concomitant chemotherapy before surgical intervention. The involvement of pre-surgical radiotherapy into the treatment algorithm increased emotional disturbances (anxiety, feelings of hopelessness) and negatively influenced patient's treatment adherence and positive expectations from the healing process. The negative psychosocial consequences appeared to be more enhanced in female patients. Despite provided information about advances of neoadjuvant radiotherapy onto success of surgical intervention, the emotional and cognitive disorders improved only slightly. The results clearly indicate that addressed communication and targeted psychosocial support has to find place before pre-surgical radiochemotherapy and as a standard part through the trajectory of the entire multimodal rectal cancer treatment.
\end{abstract}

Key words: rectal cancer, pre-surgical treatment, psychosocial morbidity

Management of rectal cancer possess major challenges concerning tumor control and anal sphincter preservation. First line surgery followed by radio chemotherapy has long been considered to be the standard treatment modality for lower tumors with a distal edge up to $6 \mathrm{~cm}$ from the anal verge. However, despite providing excellent local control, the frequent tumor recurrence, adverse high incidence of sexual and urinary dysfunction along with sphincter dysfunction and psychosocial morbidity prompted clinicians to look for alternative algorithm of rectal cancer treatment. Currently, the standard approach to management of locally advanced (T3 /T4) rectal cancer involves preoperative long-course radio chemotherapy and mesorectal tumor resection [1-4]. Recently, several clinical studies brought evidence indicating that at least $30 \%$ of patients with malignancies beginning radiotherapy with or without chemotherapy suffered from critical psychosocial distress [5-8]. Treatment-related distress can be further enhanced by a situation, when pre-surgical neoadjuvant radiotherapy is indicated. In the case of locally advanced rectal cancer, the preoperative radio chemotherapyhas shown to be medically beneficial in improving the outcome of surgery and enhancing the disease-free survival rate $[9,10]$.However, patient's expectation to be cured by the first line surgery can be negatively influenced by the decision to include neoadjuvant long-course radio chemotherapy prior to surgical intervention. From the patient's perspective such treatment algorithmindicates incurability of the disease and some patients tend to reject the proposed treatment modality [1]. The change of treatment algorithm and the feeling of hopelessness may be associated with serious multiple physical 
and emotional morbidities and enhanced distress may result in patients lack of surveillance and coping abilities.Patients who opt for up-front rectal surgery need to understand that the success of surgery depends on pre-surgical tumor shrinkage, preservation of tumor spread and prevention of adverse complications.

In light of the above consideration, this paper deals with the assessment of the pre-surgical long-course radio chemotherapy onto the psychosocial status of rectal cancer patients before and after of radiotherapy administration. Based on the previous observations we hypothesized

that there would be a difference among occurrence of anxiety, depression, and traumatic stress symptoms before and after radiotherapy treatment. We predicted positive outcome in patient's understanding and cooperation after informational intervention explaining the beneficial results of pre-surgical radiotherapy onto treatment results of surgery and final clinical outcome.

\section{Patients and methods}

Patients with stage T3 and T4 locally advanced resectable rectal cancer eligible for the survey were recruited from the Department of Radiology, St. Elisabeth Cancer Institute, Bratislava, Slovakia. After completion of the diagnosis, the first-line treatment modality was discussed and designed in a meeting of a multidisciplinary team. The decision to treat selected patients with the first line pre-surgical radiotherapy (with and without chemotherapy) was disclosed to patients in a personal communication. From 72 patients a group of 64 stratified patients ( 43 men, 21 women aged 54 - 76 years) were than involved into the survey. The exclusion criteria involved presence of serious co-morbidities and distant metastases, and absence in one of the check-ups. In the first line of treatment, patients were treated with long-course pre-surgical radiotherapy (Lineac, 2,0Gy/day, 5 times/week, 64 GyTD) with or without concomitant chemotherapy (5-Fu $350 \mathrm{mg} /$ $\mathrm{m} 2 /$ day). Clinical parameters of radiotherapy treatment (tumordown staging, frequency of local recurrence, sphincter preservation etc.) were analysed before surgical intervention by means of standard techniques and were included into the results. In assessing the treatment-related distress, patients completed measures of psychosocial distress symptoms (anxiety, depression, physical, marital, sexual and other symptoms) by answering questions of standardised EORTC Quality of Life (QLQ) questionnaires and the Hospitality Anxiety and Depression Scale (HADS) questionnaire.The questionnaires were distributed to patients at three intervals a) after the decision to initiate the treatment with first-line radio chemotherapy, b) after the radio chemotherapy termination and c) to limited number of patients reporting to the first check-up after surgical intervention.

The EORTC QLQ-C30.3 [12] is a 30-item self-reporting questionnaire developed to assess the quality of life of cancer patients. The questionnaire is grouped into five functional subscales (role, physical, cognitive, emotional and social functioning). In addition, there are three multi-item symptom scales (fatigue, pain, and nausea and vomiting), and two questions assessing overall quality of life (QoL). The EORTC QLQ-RC29 module [13] comprises 29 items assessing the rectal cancer-specific symptom scales (disease symptoms, side effects of treatment). According to the EORTC guidelines, the scores in Likert 1-4 scale were re-calculated to scores ranging from 0 to 100, where higher scores for the functioning scales represent a higher level of functioning and higher scores for the symptoms represent a greater extent of symptomatology.

The Hospital Anxiety and Depression Scale - HADS [14] is a 14-item self-report scale that consists of a depression and an anxiety scale, each with 7 items. It focuses on subjective disturbances of mood rather than physical signs, and aims at distinguishing depression from anxiety. The HADS gives clinically meaningful results as a psychological screening tool, in clinical group comparisons and in correlational studies with several aspects of disease and quality of life. It is sensitive to changes both during the course of diseases and in response to psychotherapeutic and psychopharmacological intervention. Finally, HADS scores predict psychosocial and possibly also physical outcome.

The significance of achieved results was analysed by means of the Kruskal-Wallis variance test [15].

Table 1. Comparison of psychosocial functioning scales $(1-100)$ in rectal cancer patients before and after pre-surgical radio chemotherapyand surgical intervention

\begin{tabular}{|c|c|c|c|c|c|c|}
\hline Scale & \multicolumn{2}{|c|}{$\begin{array}{c}\text { Mean score } \\
\text { Men } \\
\text { Before RT After RT }\end{array}$} & \multicolumn{2}{|c|}{$\begin{array}{c}\text { Mean score } \\
\text { Women } \\
\text { Before RT After RT }\end{array}$} & \multirow[t]{2}{*}{$\begin{array}{c}\mathrm{P} \\
\text { Men Women }\end{array}$} & \multirow[t]{2}{*}{$\begin{array}{c}\text { Mean score } \\
\text { after surgery } \mathrm{P}\end{array}$} \\
\hline Functioning & & & & & & \\
\hline Physical & $74,8+20,9$ & $74,3+14,3$ & $66,5+14,3$ & $71,7+10,5$ & NS NS & 77.4 NS \\
\hline Role & $81,1+16,9$ & $50,3+8,8$ & $50,3+8,8$ & $71,8+9,8$ & $<0,05<0,05<0,05$ & $86,0<0,05$ \\
\hline Emotional & $51,0+9,8$ & $68,0+7,6$ & $58,0+7,6$ & $73,5+15,8$ & $<0,05$ & $79,5<0,05$ \\
\hline Cognitive & $78,2+10,2$ & $63,7+16,1$ & $63,7+16,1$ & $62,7+14,3$ & $<0,05 \mathrm{NS}$ & $75,1 \mathrm{NS}$ \\
\hline Social & $57,0+18,0$ & $60,2+17,0$ & $60,2+17,0$ & $74,2+8,5$ & $\mathrm{NS}<0,05$ & $75,5 \mathrm{NS}$ \\
\hline Global QoL & $3,06+0,8$ & $3,77+0,8$ & $3,7+0,8$ & $4,0+0,8$ & NS NS & $4,0 \mathrm{NS}$ \\
\hline
\end{tabular}

Higher scores indicate higher level of functioning and quality of life

Global quality of life scores $1-7,1$ - very bad, 7 - excellent 


\section{Results}

Functioning and global quality of life in patients before and after radio-chemotherapy and surgery. Table 1 shows patient's functioning and global quality of life as measured by the EORTC QLQ C30.3 questionnaires at three intervals: before an after radio chemotherapy and too 19 patients reported to the first check-up after surgical treatment.

The results indicate that physical functioning did not change considerably during the course of treatment, while scores of other aims showed variability within the treatment trajectory, both in men and women: Before the start of radio chemotherapy men reported relatively high role $(81,1)$ and cognitive $(78,2)$ functioning scores. However, these values significantly dropped after neoadjuvant treatment (50,0 vers. $63,7)$. In male patients, the enhanced pre-treatment distress was expressed by low emotional functioning score $(51,0)$ and the quality of social life $(57,0)$. In men, the emotional values significantly improved after radio chemotherapy termination $(68,0)$, while social life scores remained nearly unchanged. In women the situation appeared to be slightly different: Female patients reported lower functional scores in all domains before radio chemotherapy (range $50-63$ ), while scoring in nearly all domains significantly improved after radio chemotherapy treatment. Post-treatment improvement in the global quality of life scores was not of statistical significance.

General cancer symptomatology before and after presurgicalradio chemotherapy. General symptoms of the disease, known to be expressed nearly in all malignancies in the course of disease progression [16,17] appeared to be enhanced in rectal cancer patients before neoadjuvant treatment (Table 2): Before radio chemotherapy male patients complained more frequently about enhanced fatigue, insomnia, and pain. After neoadjuvant treatment, enhanced scores in nearly all disease symptoms were remained enhanced. As in the case of psychosocial morbidity, the increased symptom scores before pre-surgical radio chemotherapy was gender related and the male/female ratio was significantly higher in female patients: In females, the high pre-treatment scoring of fatigue $(31,6)$ and pain $(24,5)$, nearly doubled after pre-surgical radio chemotherapy, while insomnia scores dropped from 41,8 to 33,3 . Before pre-surgical radio chemotherapy the male patients presented enhanced fatigue and pain symptomatology along with sleeping problems and sexual disability. In the post-treatment analysis, the symptom scores (excluding pain) increased of about 30 to $45 \%$. It is to note, that sexual problems and financial concerns were troubling mainly female patients.

After surgery, 17 patients reported to check-up at the place of investigation. Interestingly, scores of insomnia and pain were enhanced in treated patients regardless the gender. However, the small number of patients reported after surgery and participated in the survey is insufficient to take a serious conclusion

Anxiety and depression scores in patients before and after radio chemotherapy as measured by HADS questionnaire. The results comparing functioning scales and cancer symptom values indicated that pre-surgical radiotherapy is perceived by rectal cancer patients as a serious threat of incurability of their disease. Low scores of emotional functioning before radio chemotherapy have been considered as predictors of enhanced anxiosity, traumatic stress and anxio-depressive syndromeoccurrence in patients to whom the indication of neoadjuvant radio chemotherapy prior to surgical treatment has been disclosed. The anxiety and depression morbidity were assessed using the HADS scale. Cut-off scores were set up for both syndromes as following: $0-7$ non-case, $8-11$ borderline, $12-16$ severe, $17-21$ pathological. At baseline, the HADS questionnaire was distributed to all rectal cancer patients with the indication of pre-surgicalradio chemotherapy, then after the completion of the neoadjuvant treatment, and finally after surgical intervention. The results ale presented in the Table 3

Table 2. Symptom scores $(1-100)$ of rectal cancer patients before and after pre-surgical radiotherapy followed by surgery as measured by the EORTC QLQ C29 questionnaire

\begin{tabular}{|c|c|c|c|c|c|c|}
\hline Scale & \multicolumn{2}{|c|}{$\begin{array}{c}\text { Mean score } \\
\text { Men } \\
\text { Before RT After RT }\end{array}$} & \multicolumn{2}{|c|}{$\begin{array}{c}\text { Mean score } \\
\text { Women } \\
\text { Before RT After RT }\end{array}$} & $\begin{array}{c}\mathrm{P} \\
\text { Men Women }\end{array}$ & \multirow[t]{2}{*}{$\begin{array}{c}\text { Mean } \\
\text { score } \\
\text { after } \\
\text { surgery P }\end{array}$} \\
\hline \multicolumn{6}{|l|}{ Symptoms } & \\
\hline Fatigue & $29,3+14,3$ & $42,5+20,9$ & $31,6+9,8$ & $45,7+14,7$ & $<0,05<0,05$ & $37.4 \mathrm{NS}$ \\
\hline Nausea & $8,5+15,1$ & $7,7+12,4$ & $7,6+15,4$ & $6,7+20,9$ & NS NS & 6,0 NS \\
\hline Pain & $27,7+9,6$ & $29,6+8,5$ & $24,5+12,0$ & $42,8+19,0$ & NS $<0,05$ & $55,5<0,05$ \\
\hline Dyspnoea & $9,4+33,6$ & $11,9+23,1$ & $14,1+20,3$ & $9,6+17,0$ & NS NS & $15,1 \mathrm{NS}$ \\
\hline Insomnia & $23,6+10,0$ & $44,4+14,2$ & $41,8+9,8$ & $33,3+15,5$ & $<0,05<0,05$ & $55,5<0,05$ \\
\hline Appetite & $14,4+28,3$ & $18,5+26,5$ & $16,7+18,4$ & $19,5+16,3$ & $<0,05 \mathrm{NS}$ & 14,0 NS \\
\hline Constipation & $12,7+33,1$ & $12,0+23,1$ & $9,97+6,4$ & $10,0+12,3$ & NS NS & $11,0 \mathrm{NS}$ \\
\hline Diarrhoea & $6,4+22,4$ & $5,2+18,7$ & $5,2+12,1$ & $4,0+20,1$ & NS NS & $8,8 \mathrm{NS}$ \\
\hline Sex problem & $24,1+19,0$ & $27,4+24,5$ & $32,5+25,7$ & $44,7+25,2$ & NS $<0,05$ & $48,4 \mathrm{NS}$ \\
\hline Finances & $8,2+23,7$ & $8,6+22,2$ & $22,4+5,1$ & $32,2+14,7$ & NS $<0,05$ & NS NS \\
\hline
\end{tabular}

Higher scores indicate higher degree of symptoms 
Table 3. Hospital Anxiety and Depression Scale (HADS) responses from patients with locally advanced rectal cancer before and after preoperative radiotherapy

\begin{tabular}{|c|c|c|c|c|c|c|c|c|}
\hline \multirow[t]{2}{*}{ Anxiety } & \multicolumn{2}{|c|}{$\begin{array}{c}{ }^{*} \text { Score } \\
\text { before RT }\end{array}$} & \multicolumn{2}{|c|}{$\begin{array}{l}{ }^{*} \text { Score } \\
\text { after RT }\end{array}$} & \multicolumn{2}{|c|}{$\begin{array}{c}\text { Ratio } \\
\text { Men/women }\end{array}$} & \multirow{2}{*}{\multicolumn{2}{|c|}{ SD P }} \\
\hline & Men & Women & Men & Women & -RT & $+\mathrm{RT}$ & & \\
\hline Tension, wound-up feeling & 2,0 & 2,7 & 1,9 & 2,0 & 0,74 & 0,90 & 0,113 & $<0,05$ \\
\hline Frightened feeling & 1,8 & 2,0 & 1,2 & 1,8 & 0,88 & 0,91 & 0,021 & NS \\
\hline Worrying thoughts & 1,6 & 2,1 & 1,1 & 1,4 & 0,76 & 0,78 & 0,014 & NS \\
\hline Feeling of easy relaxation & 1,3 & 1,8 & 1,8 & 1,9 & 0,61 & 0,94 & 0,233 & NS \\
\hline „Butterflies“ in stomach & 1,4 & 1,8 & 1,0 & 1,2 & 0,77 & 0,83 & 0,042 & NS \\
\hline Restlessness & 2,0 & 2,2 & 1,6 & 1,9 & 0,90 & 0,90 & 0,000 & NS \\
\hline Panic & 1,1 & 1,2 & 0,4 & 0,7 & 0,83 & 0,57 & 0,183 & NS \\
\hline${ }^{* *}$ Mean value & 11,2 & 13,8 & 9,0 & 10,9 & 0,81 & 0,83 & 0,014 & $<0,05$ \\
\hline Depression & \multicolumn{2}{|c|}{$\begin{array}{c}\text { Score } \\
\text { Before RT }\end{array}$} & \multicolumn{2}{|c|}{$\begin{array}{c}\text { Score } \\
\text { After RT } \\
\text { Men Women }\end{array}$} & \multicolumn{2}{|c|}{$\begin{array}{c}\text { Ratio } \\
\text { men/women } \\
\text {-RT +RT }\end{array}$} & & \\
\hline Still enjoying thinks & 0,8 & 1,2 & 0,9 & 1,1 & 0,66 & 0,82 & 0,113 & NS \\
\hline Laughing ability & 1,0 & 1,3 & 1,4 & 1,3 & 0,76 & 0,90 & 0,048 & NS \\
\hline Feeling cheerful & 1,3 & 2,0 & 1,2 & 1,8 & 1,06 & 0,66 & 0,282 & $<0,05$ \\
\hline Slow-down feeling & 1,8 & 1,3 & 0,8 & 1,2 & 1,38 & 0,66 & 0,509 & $<0,05$ \\
\hline Interest lost in appearance & 0,3 & 1,4 & 0,4 & 1,9 & 0,21 & 0,20 & 0,007 & NS \\
\hline Future & 1,2 & 1,5 & 2,1 & 1,6 & 0,80 & 1,78 & 0,692 & $<0,05$ \\
\hline Reading, listening enjoyment & 0,5 & 0,9 & 0,8 & 0,3 & 0,55 & 2,66 & 1,491 & $<0,05$ \\
\hline${ }^{\star *}$ Mean value & 6,8 & 9,6 & 7,5 & 9,3 & 0,81 & 0,68 & 0,091 & NS \\
\hline
\end{tabular}

${ }^{*}$ Mean values in Likert scale $0-3$

${ }^{*}$ Total mean score of anxiety or depression $0-21$

The HADS testing revealed that patients displayed symptoms of tension, frightening feeling, worrying thoughts, nervousness and restlessness mainly before pre-surgicalradio chemotherapy. The difference in the mean anxiety scores over normal cut-off level (7 points) in men and women (11,2 vs. 13,8 ) indicate that the feeling of anxiety more intensively percieved by female patients. After pre-surgicalradio chemotherapy, significant improvements on anxiety symptoms as well as the mean anxiety values were recorded in both patient groups. Despite the improvement of the psychosocial status, anxiety indicator scores remained high.

In contrast to enhanced anxiety feeling, depression mood was less vulnerable than anxiety and worrying before and after pre-surgicalradio chemotherapy Again, depression variables and the mean depression scoring was higher in women than in men patients, however, without statistical significance.

Rationale of pre-surgicalradio chemotherapy: Clinically relevant decrease in rectal cancer growth and adverse events of surgical intervention. The relevance of neoadjuvant radio chemotherapy in term of rectal cancer operability have been demonstrated by multicenter international surveys [ for ref. see 2]. The improved clinical outcome of pre-surgical treatment with long-course radiotherapy with and without concomitant chemotherapy in 64 patients with locally advanced rectal cancer is presented in Table 4.

Table 4. Clinically relevant improvement of rectal cancer treated by long-course pre-surgical radiotherapy with and without concomitant chemotherapy

\begin{tabular}{|c|c|c|c|c|c|}
\hline \multirow{3}{*}{$\begin{array}{l}\text { Clinical } \\
\text { outcome }\end{array}$} & \multicolumn{4}{|c|}{ Relevant improvement } & \multirow[b]{3}{*}{$\mathrm{P}$} \\
\hline & \multicolumn{2}{|c|}{ Radiotherapy } & \multicolumn{2}{|c|}{ Radiochemotherapy } & \\
\hline & Patients & Per cent & Patients & Per cent & \\
\hline Tumordown staging & 29 & 46 & 39 & 61 & $<0,05$ \\
\hline Sphincter preservation & 30 & 47 & 31 & 49 & NS \\
\hline Pathol. complete response & 8 & 13 & 12 & 18 & $<0,05$ \\
\hline Early local recurrence & 10 & 15 & 3 & 5 & NS \\
\hline Acute toxicity & 8 & 13 & 17 & 29 & $<0,05$ \\
\hline
\end{tabular}


The results are clearly indicating superiority of the concomitant pre-surgical radio-chemotherapy over radiotherapy alone in the treatment of rectal cancer. The down staging of tumors treated with radiotherapy alone has been recorded in $46 \%$ treated patients, while the treatment efficiency was enhanced by a combination of radiotherapy and chemotherapy in $61 \%$ patients. The clinical data of sphincter preservation and pathological complete response confirmed the superiority of pre-surgical radiochemotherpy.

\section{Discussion}

As cancer is a life-threatening disease usually involving aggressive and intrusive treatment, cancer patients frequently experience stress-determined psychosocial co-morbidities and emotional alterations such as anxiety, depression, fatigue, sleep disturbances, apathy and cognitive and sexual disorders [18]. The consequence of psychosocial distress in patients with cancer include reduction of treatment adherence and coping capability, and impairment quality of life. Although the unrecognised cancer-related distress is harmful for patient's disease-free survival, little interest is paid to emotional status of cancer patients before and during anticancer treatment [19]. Clinical studies repeatedly showed that different types of treatments and treatment modalities have different impact on patient's psychosocial status [20]. Especially, radiotherapy is evoking serious psychosocial dysfunction, stress and anxio-depressive syndrome [21]. During the past three decades it has been repeatedly demonstrated that radiotherapy alone or with concomitant chemotherapy and applied in form of neoadjuvant treatment before surgery in patients with resectable rectal cancer, have the best efficacy in term of tumor shrinkage and sphincter preservation. It has been shown that the long-course neoadjuvant radio chemotherapy results in substantial tumor down-staging, is tolerable and permits tumor removal by surgical intervention $[22,2)$. On the other hand, stressful perception of the treatment itself and uncertainty in the expectation of its effectivity may result in serious psychosocial distress resulting in psychosocial co-morbidities and behavioural alterations such as anxiety, depression, sleep disturbances. fatigue, pain, cognitive and sexual disorders. Pelvic radiotherapy even combined with chemotherapy is perceived by patients as a serious danger for their vital functions. The pre-surgical combination modality is expected to be a badly tolerated stress-inducing event, since patients perceive their cancer as more severe and as a result they may show higher stress symptomatology.

In an attempt to verify the hypothesis, patients who agreed to participate in the survey were asked to complete the questionnaires at four time points; prior to starting pre-surgical radio chemotherapy treatment, at the end of radiochemotherapy, and again at the first post-surgical clinical inspection.Our results confirmed this proposition indicating that patients treated with neoadjuvant radiotherapy were af- fected by enhanced symptoms of anxiety and depression in time, when the indication of radionchemotherapy as a first line treatment was disclosed. As a consequence, patients reacted by enhancement of clinical cancer symptomatology and low level of overall quality of life. In accordance with the previously reported data [6], the quality of life scores remained low during the whole course of treatment regardless patients gender.

In the survey, female patients have shown higher level of anxiety and depression symptoms compared with males both before and after radiotherapy: Before pre-surgical radio chemotherapy physical $(74,8$ vs.66,5), role $(81,1$ veers $50,3)$ and cognitive $(78,2$ vs. 63,7$)$ functioning was lower in female patients. Likewise, female patients suffered more from anxiety $(11,2$ vs. 13,8$)$ and depression $(6,8$ vs. 9,6$)$ than men as reported in the HADS questionnaire. The symptom scores were enhanced in accordance with psychosocial disturbances.

Our results, showing qualitative differences in the psychosocial disturbances among men and women treated with radio chemotherapy are in line with previous studies: Stehlen and co-workers [23] demonstrated higher anxiety and pain scores reported by female patients during pre-surgical radiotherapy. The relevant predictor variables of enhanced stress symptomatology included gender, marital status and age. Female patients treated for cancer with pre-surgical radiotherapy suffered more from anxiety, depression, insomnia and dysfunctions in emotional functioning $[24,25]$. The authors, however, did not measure baseline psychosocial disturbances before radiotherapy treatment initiation. Our results indicated that in female patients the highest level of stress symptomatology occurs in the pre-treatment period, when the need of pre-surgical radiotherapy has been disclosed. It is to note that information intervention alone about the clinical benefit of the pre-surgical radio chemotherapy, is insufficient in protecting patients from enhanced stress. This suggests that all patients regardless the gender, but especially women expecting pre-surgical radiotherapy and having enhanced clinical symptomatology, should be routinely screened for psychosocial distress.In addition to the approved need of psychosocial support during the whole trajectory of cancer, our results are underlining the importance of targeted psychological intervention for patients undergoing pre-surgicalradio chemotherapy.

Enhanced chronical anxiety, depression, emotional and cognitive dysfunction may have negative impact on cancer patient'ssurveillance, coping ability, treatment efficiency, overall quality off life and cancer-related survival time [26,27]. This in turn means that medical care providers must be aware of the psychosocial burden of different severity troubling patients and their relevant during the whole course of the disease, from disclosure of cancer diagnosis, through treatment, until cancer progression, palliative care, terminal phase and death. The pre-surgicalradio chemotherapy remains to be one of the critical events. Therefore. recognising the awareness of 
the psychosocial changes, emphatic targeted communication, informational, emotional and behavioural interventions should be offered by doctors, nurses, psychologists and oncology social workers [28] in an encouraging atmosphere. The improvement of quality of life, emotional status and treatment outcome of patients during and after psychosocial intervention should be analysed in more details.

\section{References}

[1] BIRGISSON H, PAHLMAN L, GUNNARSSON U. Adverse effects of preoperative radiation therapy for rectal cancer: long-term follow-up of the Swedish Rectal Cancer Trial. J ClinOncol, 2005; 23: 8697-8705 http://dx.doi.org/10.1200/ LCO.2005.02.9017

[2] KRAJCOVICOVA I, BOLJESIKOVA E, SANDOROVA $\mathrm{M}$, ZAVODSKA A, ZEMANOVA $\mathrm{M}$ et al. Preoperative radiotherapy of locally advanced rectal cancer: Clinical outcome of short-course and long-course radiotherapy with or without concomitant chemotherapy. Klin. Onkol. 2012; 25: 364-369

[3] SAUER R, LIERSCH T, MERKEL S, FIETKAU R, HOHENBERGER W. et al. Preoperative versus postoperative chemoradiotherapy for locally advanced rectal cancer: results of the German CAO/ARO/AIO-94 randomized phase III trial after a median follow-up of 11 years. J ClinOncol 2012; 30: 1926-33. http://dx.doi.org/10.1200/JCO.2011.40.1836

[4] GERARD JP, CHAPET O, NEMOZ C. Improved sphincter preservation in low rectal cancer with high-dose preoperative radiotherapy: the Lyon R96-02 randomized trial. J ClinOncol 2004; 22(12): 2404-2409. http://dx.doi.org/10.1200/ JCO.2004.08.170

[5] STEHLEN S, HOLLENHORST H, SCHYMURA B, HERSCHBACH P, AYDEMIR U et al. Psychosocial stress in cancer patients during and after radiotherapy

[6] TAKAMUSHI T, HONDO M, NISHIMURA K, KITANI A, YAMAMOTO T et al.: Evaluation of quality of life and psychosocial response in cancer patients treated with radiotherapy. Radiat, Med. 2008; 26: 396-401 http://dx.doi.org/10.1007/ s11604-008-0248-5

[7] KIRCHHEINER K, CZISKA A, OIMICNY-SELINGER E, LUTGENDORF-CAUCIG C, SCHMIDT MP et al.: Physical and psychosocial support requirements of 1.500 patients starting radiotherapy. Strahlenther. Onkol. 2013; 189: 424-429 http://dx.doi.org/10.1007/s00066-013-0329-y

[8] BEAD KH, BATIHA A, AL_SAUSSI MS, ALHALAIDA F, AL-BASTHAVI M: Impact of radiotherapy treatment of Jordanian cancer patients: quality of life and fatigue. Internat. J. Advant. Nurs. Stud. 3: 6-12, 2014

[9] SCHRAG D.: Evolving role of neoadjuvant therapy in rectal cancer.Curr. Treatment Options Oncol. 2013; 14: 350-364 http://dx.doi.org/10.1007/s11864-013-0242-8

[10] WAGNER TD. Rectal cancer: a truly multidisciplinary challenge. J GastrointestOncol 2014; 5: 323-325

[11] PUCIARELLI S, BIANKO PT, EFFICACE F, SERPENTINI S, CAPRICI C et al. Patient-reported outcome after neoadjuvant chemoradiotherapy for rectal cancer Annals Surg. 2011; 253: 71 - 77 http://dx.doi.org/10.1097/ SLA.0b013e3181fcb856

[12] AARONSON NK, KAASA S, AHMEDZAI S, BERGMAN B, BULLINGER $M$ et al. The European Organization for Research and Treatment of Cancer QLQ-C30: a qualityoflife instrument for use in international clinical trials in oncology. J Natl Cancer Inst, 1993; 85: 365-376 http://dx.doi.org/10.1093/jnci/85.5.365

[13] GURJAL S, CONROY T, FLEISSCHNER C, SBEER O, KING PM et al: Assessing quality of life in patients with colorectal cancer: an update of the EORTC quality of life questionnaires. Europ. J. Cancer 2007; 43: 1564-1573 http://dx.doi. org/10.1016/j.ejca.2007.04.005

[14] ZIGMOND AS, SNAITH RP. The hospital anxiety and depression scale. ActaPsychiatrScand, 1983; 67: 361-370 http:// dx.doi.org/10.1111/j.1600-0447.1983.tb09716.x

[15] KATZ BM, MCSWEENEY M: A multivariable Kruskal-Wallis test with post hoc procedure. Multivariab. Behavior. Res. 1998; 15: 281-297 http://dx.doi.org/10.1207/s15327906mbr1503 4

[16] TEUNISSEN S, WESKE RW, KRUITWAGEN C, DeHAYES H et al. Symptpomrevalence in patients with curable cancer. A system review. J. Pain Symptom Managem. 2007; 34: 94 - 102 http://dx.doi.org/10.1016/j.jpainsymman.2006.10.015

[17] REEWE BB, MITCHEL SR, DUECK NC. Recommended patient-reported care set of symptoms to measure in adult cancer treatment trials. Nat. Cancer Inst. 2014; 106: 1093 1101. doi: 10.1093/nci/dju.12q

[18] HINZ A, KRAUSS O, HAUSS JP, HOCKEL M, KORTMANN RF et al. Anxiety and depression in cancer apatients compared with the general population. Europ. J. Cancer Care 2011; 19: 522-529 http://dx.doi.org/10.1111/j.1365-2354 .2009.01088.x

[19] AVERYL JC, NISHIMOTO PW. Adressing sexual dysfunction in colorectal cancer survivorship care. J. Gastrointest. Oncol. 2014; 5: 388-394

[20] PEREIRA GM, FUGUEIREDO AP, FINCHAM F. Anxiety, depression, traumatic stress and quality of life in colorctal cancer after different treatment. A study with Portuguese patients and their partners. Europ. J. Oncol. Nursing 2011 doi: 10.1016/j.ejon.2011.06.006

[21] STIEGELI HE, RAUCHOR AV, SANDERMAN RS. Psychologicl functioning in cancer patients treated with radiotherapy. Pat. Educat. Consul. 2004; 52: 131-141 http:// dx.doi.org/10.1016/S0738-3991(03)00021-1

[22] MCLACHLAN S, FISCHER R, MCLURE B. A comparison of quality of life in patients with $\mathrm{T} 3$ rectal cancer receiving short-course vs long-course preoperative radiation. A TransTasman radiation oncology group trial (TROG 01.04) Proc. Amer. Soc. ClinOncol 2008; 26: 202 - 244

[23] SEHLEN S, HOLLENHORST H, SCHYMURA B, HERSCHBACH P et al. Psycosocial stress in cancer patients during and after radiotherapy. Strahlenther. Onkol. 2003; 179: 175-180 http://dx.doi.org/10.1007/s00066-003-1018-Z

[24] GUO Z, TANG HY, LI H, TAN SK et al. The benefits of psychosocial interventions for cancer patients undergoing radiotherapy Health Qual. Life Outcomes 2013; 17: 121-129 http://dx.doi.org/10.1186/1477-7525-11-121 
[25] HESS CB, SINGER M, KHAKU A, MALLNOU J et al. Optimal frequency of psychosocial distress screening in radiation oncology J. Oncol. Practice 2015; 11: 298-302 http://dx.doi. org/10.1200/JOP.2014.003392

[26] KROENKE CH, KUBZANSKY LD, SCHERNHAMMER ES, HOLMES MD, KAWACHI I. Social network, social support, and survival after breast cancer diagnosis. Journal of Clinical Oncology. 2006; 24: 1105-1111 http://dx.doi.org/10.1200/ JCO.2005.04.2846
[27] PHILLIPS KA, OSBORNE RH, GILES GG, DITE GS, APICELLA $C$ et al. Psychosocial factors and survival of young women with breast cancer: a population-based prospective cohort study Journal of Clinical Oncology. 2008; 26: 4666-4671 http://dx.doi.org/10.1200/JCO.2007.14.8718

[28] HYOSP G, CHRIST C, LESSNER C, BEHAR L. Handbook of oncology social work. Psychosocial care for people with cancer. Oxford University Press (L. Behar, ed.), 2015 ISBN 978-0-19-994192-6 